\title{
The Theory of Epistemic Justification and the Theory of Knowledge: A Divorce
}

\author{
Anthony Robert Booth
}

Received: 29 October 2009/Accepted: 27 October 2010/Published online: 17 December 2010

(C) The Author(s) 2010. This article is published with open access at Springerlink.com

\begin{abstract}
Richard Foley has suggested that the search for a good theory of epistemic justification and the analysis of knowledge should be conceived of as two distinct projects. However, he has not offered much support for this claim, beyond highlighting certain salutary consequences it might have. In this paper, I offer some further support for Foley's claim by offering an argument and a way to conceive the claim in a way that makes it as plausible as its denial, and thus levelling the playing field. The burden of proof then lies with those who seek to deny Foley's radical suggestion.
\end{abstract}

Richard Foley has suggested that the search for a good theory of epistemic justification and the analysis of knowledge should be conceived of as two distinct projects. However, he has not really offered an argument for this claim. Instead, he has offered the idea that externalists and internalists are engaged in different projects (the former in the analysis of knowledge, the latter in the theory of epistemic justification) as an "interesting reading" (Foley 2001, p. 13) of what many contemporary epistemologists are doing, and as a way of resolving certain standing (and seemingly intractable) debates (see also Foley 2003, 2004). At most, the suggestion can be seen as an inference to the best explanation, given the current state of the discipline.

In this paper, I will offer an argument for the strong claim that the search for a good theory of epistemic justification and the analysis of knowledge are logically independent projects; in other words, epistemic justification is neither necessary nor sufficient for knowledge, and there is independent motivation for why epistemologists should be concerned with developing theories of epistemic justification (call this thesis LIC - the logical independence claim). Or, rather, I want to argue that the

\footnotetext{
A. R. Booth $(\bowtie)$

Department of Philosophy, Utrecht University, Heidelberglaan 6, 3584 CS Utrecht, The Netherlands e-mail: Anthony.Booth@phil.uu.nl; arbooth@fastmail.fm
} 
proponent of LIC has no extra theoretical burden that his opponent does not have, i.e. that LIC is as likely to be true as its negation. Here is a summary of the argument:

(1) A justification condition for knowledge cannot rule out all cases of epistemic luck.

(2) If a justification condition is part of an analysis of knowledge, then it must also have some further, anti-luck condition(s).

(3) Since the anti-luck conditions, on their own, eliminate all cases of epistemic luck, then a justification condition for knowledge must be there do some other work than eliminating epistemic luck.

(4) A plausible account of why epistemologists talk about epistemic justification is that it accounts for (what I will call) the deontic intuition.

(5) The deontic intuition does not have to be an intuition that figures in the analysis of knowledge, i.e. we have the deontic intuition regardless of how we define knowledge.

(6) Thus, there is motivation to talk about justification even if justification is not a necessary condition for knowledge.

(7) If a justification condition is there to take care of the deontic intuition, then we have the resources to explain away why we might think that the deontic intuition figures in an analysis of knowledge (i.e. why justification is a necessary condition for knowledge).

(8) It is as plausible to maintain LIC as it is to maintain its negation.

Let me now try to explain the argument. Consider why many think that justification figures in epistemology. That is something like the following: in analyzing the concept of knowledge, we come to realize that having a belief that $p$ and that $p$ are necessary, but not sufficient, conditions for knowing that $p$. Why are they not sufficient? Because the definition would rule lucky true belief as knowledge, and we have a strong intuition that lucky 'knowledge' is not really knowledge. My belief that the conservative party win the next general election in the UK, for example, is not knowledge if the grounds for which I hold that belief are that I saw it in a dream, even if by chance my belief turns out to be true. Thus in order to rule-out lucky 'knowledge', we think that we need a further condition: the justification condition. ${ }^{1}$ Of course, as it has turned out, the justification condition is

\footnotetext{
${ }^{1}$ Here is an encyclopedia entry on the matter: "Why not say that knowledge is true belief? The standard answer is that to identify knowledge with true belief would be implausible because a belief that is true just because of luck does not qualify as knowledge[...]Let us refer to a belief's turning out to be true because of mere luck as epistemic luck. It is uncontroversial that knowledge is incompatible with epistemic luck. What, though, is needed to rule out epistemic luck? Advocates of the JTB account would say that what is needed is justification. A true belief, if an instance of knowledge and thus not true because of epistemic luck, must be justified" (Steup 2006). However, it may not be historically accurate to think that this is the univocal reason for why justification has figured in epistemology. For instance, A.J. Ayer in his The Problem of Knowledge famously suggested that we ought to construe justification in deontological terms as "a right to be sure"; it is unclear whether we need such a condition, according to Ayer, just in order to rule out lucky true beliefs as cases of knowledge or whether it satisfies a further deontic requirement. Those who are inclined to favour the latter view (whether or not it was Ayer's) can enter the argument at premise (4). Thanks to an anonymous reviewer at Erkenntnis for pointing this out to me.
} 
not up to the task, as those famous Gettier cases showed us, since we can have lucky justified true beliefs. Indeed, it is because the justification is supposed to rule-out lucky knowledge that Gettier cases are so vitiating; they show that the justification condition is not doing the job it was meant to do, i.e. rule-out all cases of epistemic luck.

Further, consider the following problem: a justified belief is not guaranteed to also be a true belief - there are such things are justified, false beliefs. The reason for this is that if all justified beliefs are true and all unjustified beliefs false, then there is no need to talk about justification in an analysis of knowledge (we only need to talk about true beliefs cf. David 2001; Maitzen 1995). Further, if all justified beliefs are necessarily true beliefs, then we risk skepticism-the standards of justification would be so high that only an unsatisfactory number of our beliefs would count as being justified. ${ }^{2}$ However, if we are fallibilists about justification, then we will always be prone to the challenge from Gettier. This is because if justification does not guarantee truth, then it is possible for a justified belief to be true by accident (something like this point is made by Merricks 1995). In other words, as long as justification is fallible, epistemic luck will not be ruled-out. So it seems that justification must be infallible if it is to be an adequate anti-luck condition, but if justification is infallible we are on a short route to skepticism.

Now, consider the possible modern ${ }^{3}$ responses to this dilemma. First of all, we could just eschew the justification condition in favour of a better anti-luck condition, such as a "safety" or "truth-tracking" condition. Or, secondly, we could add such a modal condition to the justified, true belief account (call the account in this second option, JTB+).

In $\mathrm{JTB}+$, justification cannot be there to accommodate the anti-luck intuition. This is because the ' + ' condition is doing the anti-luck work. Even if justification does rule out some cases (or some kinds) of epistemic luck, these are not cases which the ' + ' condition fails to eliminate. Since the ' + ' condition is stronger than the justification condition when it comes to eliminating luck, then justification in $\mathrm{JTB}+$ must be there to do something other than taking care of the anti-luck intuition, on pain of being redundant. The same is true of an account that has justification plus some other condition (as a conjunct) do the anti-luck work. Why insist that we need justification, when there are better anti-luck conditions that can do all the anti-luck work on their own? So what else is the justification condition there to do? Should we then just leave it out of the analysis of knowledge? ${ }^{4}$

If epistemology is solely concerned with providing a complete analysis of knowledge, then the strategy of leaving out talk of epistemic justification seems somewhat counter-intuitive. Something important seems to have been left out of our

\footnotetext{
${ }^{2}$ Another way of putting the point would be through Sosa's famous New Evil Demon problem: if two subjects $\mathrm{Q}$ and $\mathrm{R}$ come about their beliefs in exactly the same (epistemically praiseworthy) fashion, but $\mathrm{Q}$ happens to be in a world governed by an Evil Demon and R does not, we do not think that $R$ is epistemically justified and Q not so. And we don't think so despite the fact that Q's beliefs would be systematically false.

${ }^{3}$ I am assuming that the early responses to Gettier fall prey to this dilemma, for more see Merricks (1995).

${ }^{4}$ Some have argued for precisely this, cf Sartwell (1992).
} 
cognitive lives; a residual intuition seems to have been unaccounted for. What is it? I propose that it is the intuition that if it is our fate to be believers, then we ought to believe responsibly, that we have obligations/duties/requirements with respect to our beliefs. We feel that we are obliged to believe in accordance with the available evidence, for instance, and only when we do so are we epistemically justified in having a particular belief; such that we feel, for that reason, that the beliefs of Holocaust deniers, creationists, and members of the flat earth society (for example) are epistemically unsalutary. In short, we feel we ought to have justified beliefs and we want to know how. Call this the deontic intuition. ${ }^{5}$

But we feel the need to have justified beliefs regardless of whether or not justification is a necessary condition for knowledge, such that the deontic intuition is not necessarily there as part of the analysis of knowledge. If this is true, then we have motivation for talking about justification even if it turns out that justification is not a necessary condition for knowledge, since we have the deontic intuition regardless of how we define knowledge, and justification is there to take care of this intuition. But this also gives us the resources for how to think that justification is not in fact a necessary condition for knowledge. To see this, consider whether there might be another intuition (different to the anti-luck and deontic intuitions) that motivated justification talk in a JTB + account. It seems very hard to imagine what such an intuition might be. Imagine that a believer has a $\mathrm{TB}+$ and has satisfied the deontic intuition with regard to his belief, what else is there to demand of the believer? Nothing, it seems to me. But suppose that we just have a brute intuition that justification is a necessary condition for knowledge. If the deontic intuition is independent of the analysis of knowledge, the defender of LIC has the resources to explain away such an intuition, in other words, show that the intuition is defective in some way, in the same manner in which we can explain why illusions should not be considered to be cases of veridical perception. She can claim that it is a mistaken application of the deontic intuition (mistaken in applying it to the analysis of knowledge) which we are led into making because of the errant assumption that

\footnotetext{
5 Jonathan Sutton has argued (Sutton 2005, 2007) that we can account for such deontic requirements even if we drop talk of epistemic justification, and to paraphrase him "stick to what we know". According to him, one is only deontologically justified in believing that $p$ if one knows that $p$. This means that one cannot, after all, have justified, false beliefs. His argument for this crucially involves making a distinction between obligation and blameworthiness; such that we can re-interpret traditional cases where it was claimed that a subject had a justified, false belief (cases such as in Sosa's New Evil Demon Problem) as cases where a subject has a blameless belief, but has nevertheless violated his intellectual obligations (i.e. does not have a justified belief that $p$ ). Elsewhere we have argued (Booth and Peels forthcoming) that responsible belief is blameless belief, so that the distinction cannot be made. But, briefly, Sutton motivates this distinction via appeal to teaching children their obligations; we do so even though those children might still be incapable of recognizing those obligation (and so are blameless in violating them), yet that does not mean those obligations are not there, "we do not create those obligations by our instruction" (Sutton 2005, p. 371). However, Sutton does not address why we cannot diagnose the case in a way that does not pull apart blameworthiness and obligation: we can simple diagnose the 'obligations' here are proto-obligations, or prima facie obligations, which are not real obligations, but bear resemblance to them. Further, a lot will depend on what account of obligation one is working with, such that on a Strawsonian account, for instance (where to be responsible or not just is to be the proper subject of the reactive attitudes of blame and praise) the distinction does not make sense. Finally, Sutton also owes us an account of how deontological justification would saliently differ, under his analysis, to nondeontological accounts.
} 
justification is there to take care of luck, i.e. the long history of the idea that justification is a necessary condition for knowledge. So it seems to be a hasty generalization from the idea that justification can eliminate some cases of luck, and that knowledge is incompatible with luck, that justification must be part of a definition of knowledge. Here is an historical example of this happening: in the Meno, we find Socrates arguing that justified true belief is more valuable than mere true belief because it makes belief (about the route to Larissa, for instance) more reliable, i.e. less likely to be true by chance. From this, Socrates errantly generalizes that justification must be a necessary condition for knowledge. ${ }^{6}$ Obviously, the fact that justification can rule out some cases of luck, does not rule out there being better anti-luck conditions which will supersede it and thus render it obsolete.

Yet leaving justification out of epistemology altogether seems counter-intuitive, so we think it must be part of a definition of knowledge. But a proponent of LIC can insist that leaving a justification condition out of the analysis of knowledge need not mean that justification does not figure in epistemology. It does as a means to account for the deontic intuition, an intuition independent of the project of defining knowledge. Still, one may wonder how one can be engaging in epistemology if one is not trying to define knowledge. One might think that epistemology just is defining knowledge. I think this would considerably impoverish the work of epistemologists; in recent work William Alston $(1993,2005)$ has argued in favour of pluralism when it comes to epistemic justification, in his words, "we should abandon the idea that there is something or other properly called 'epistemic justification'” (Alston 1993, p. 527). The idea is that there is not enough pre-theoretical agreement about what counts as epistemic justification between competing theorists, such that one cannot settle the debate between, say, internalism and externalism, about what really is epistemic justification without begging the question. Instead, what competing theorists are doing, according to Alston, is: "highlighting, emphasizing, "pushing" different concepts, all called 'justification'. It seems...that they are selecting different epistemic desiderata, or packages thereof, as deserving the honorific title 'justification'" (Alston 1993, p. 534). I propose that a similar pluralist move can be made with respect to what we think that 'epistemology' necessarily consists in. Instead of thinking that there is one enterprise properly called 'epistemology', we should consider that there are various related projects, not necessarily reducible to one another, and none of which uniquely encapsulate what 'epistemology' is all about.

However, one may now wonder whether by appealing to Alston's pluralism on this score, I have not invalidated the idea that there is such a project as a search for a theory of epistemic justification. While I am not here necessarily committed to the view that there is one thing that should be considered as 'epistemic justification', I think that Alston's arguments support LIC, and that if LIC is true then justification is immune from Alston's argument. Consider why Alston thinks that there is no common pre-theoretical notion of justification with which to work with, which is basically that internalists and externalists are working with different such notions.

\footnotetext{
${ }^{6}$ With many thanks to anonymous reviewer at Erknenntis for this example and this way of making the point.
} 
Suppose that we try to neutrally define justification as that which turns true belief into knowledge. Suppose, further, that an externalist account of what turns true belief into knowledge was in the offing and that this account was so convincing that it would even persuade the internalists that it was the right account. Alston then asks: would the internalists thereby think that justification should be explicated in externalist terms? Absolutely not, "because a large portion of justification theorists recognize other constraints on what can count as epistemic justification, and if it should turn out that what turns true belief into knowledge does not satisfy those constraints they would not recognize it as justification" (Alston 1993, p. 536). In other words, what the internalist would conclude here is that he was wrong in thinking that justification was about what turned true belief into knowledge, not that justification is an externalist notion. Thus, concludes Alston, justification cannot be defined in a non-partisan manner as that which turns true belief into knowledge.

However, if Alston is right in his conjecture that the internalist would stop thinking about justification in terms of what turns true belief into knowledge were she to be convinced that the externalist had the right handle on the latter, then she ought not to wait until such an externalist story is forthcoming. She ought to now accept that whatever "other constraints" she has about justification, they have nothing whatever to do with answering the question "what is knowledge?" Strengthening this is the fact that Alston's counterfactual does not work the other way round. Firstly, it just seems highly unlikely that an internalist account of justification could adequately be what turns true belief into knowledge (partly due to the considerations of fallibility above) such that it would rule out cases where brains-in-vats are justified in having the beliefs they do, for instance. But even if such an account were in the offing, would the externalist then deny that justification is about what turns true belief into knowledge? While it is hard to determine the answer to this question absolutely, it is very difficult to imagine a scenario where the externalist would respond in that way. If an account of justification could give an explanation of what turns true belief into knowledge, then it would seem like the externalists' constraints on what counts as justification would be exhausted, or if justification did turn out to be something else, the externalist would cease to care about justification-she is, after all, interested in the question of what turns true belief into knowledge. So Alston's considerations should lead us to this conclusion: it is not that there are competing pre-theoretical intuitions about what counts as justification, such that a debate between internalists and externalists cannot be solved; rather, internalism and externalism are answers to different questions: what is justification and what is knowledge. Only the former need involve the notion of justification. So long as we make this distinction, and we think that investigating the nature of epistemic justification is a project worth pursuing, there is no need to abandon talk of justification in epistemology.

But what if we have the intuition that knowledge entails justified belief because we think that knowledge has a deontic component, such that in JTB+, perhaps, justification is there to take care of the "knowledge is deontic" intuition (call this the $K D$ intuition)? Maybe we do have this intuition, but an account that takes care of this intuition is theoretically no better than the account just canvassed. That is, the supporter of LIC has the resources to explain away this intuition in the same manner 
in which she has the resources to explain away the brute intuition that knowledge entails justification. That is, she can claim it is a misapplication of the deontic intuition. Notice that the deontic intuition is not the same intuition as the $K D$ intuition. If we have the $K D$ intuition, then we are likely to have the deontic intuition also (since thinking that knowledge must have a deontic component, satisfied by the justification condition, entails thinking that one ought to have justified beliefs, in so far as one ought to (or wants to) have knowledge). And if we have the deontic intuition, we also have the means to explain away the $K D$ intuition, and we can do so without sacrificing anything we might demand from a believer, viz. that he needs to have a $\mathrm{TB}+$ and have satisfied the demands of the deontic intuition with respect to his belief. Thus, assuming that a theory that can explain away a putative intuition is no worse than one which heeds it, we have as much reason to think that LIC is true as its negation. And if Foley is right that adhering to LIC has the theoretical advantages that he says it has, then, surely, we ought to accept it.

Acknowledgments With thanks to three anonymous reviewers at Erkenntnis, Rik Peels, Herman Philipse, Darrell Rowbottom and audiences at the Dutch Research Seminar in Analytic Philosophy in Utrecht, The 2nd Workshop in Analytic Philosophy at the Free University, Amsterdam, and at a departmental colloquium at Eindhoven University for their many helpful comments and suggestions on earlier versions of this paper.

Open Access This article is distributed under the terms of the Creative Commons Attribution Noncommercial License which permits any noncommercial use, distribution, and reproduction in any medium, provided the original author(s) and source are credited.

\section{References}

Alston, W. P. (1993). Epistemic desiderata. Philosophy and Phenomenological Research, 53, 527-551.

Alston, W. P. (2005). Beyond 'justification': Dimensions of epistemic evaluation. Ithaca, NY: Cornell University Press.

Booth, A. R., \& Peels, R. (forthcoming). "Why responsible belief is blameless belief". Journal of Philosophy.

David, M. (2001). Truth as the epistemic goal. In M. Steup (Ed.), Knowledge, truth and duty. Oxford: Oxford University Press.

Foley, R. (2001). Intellectual trust in oneself and others. Cambridge: Cambridge University Press.

Foley, R. (2003). "Justified belief as responsible belief”. In M. Steup \& E. Sosa (Eds.), Contemporary debates in epistemology. Oxford: Wiley-Blackwell.

Foley, R. (2004). "A trial separation between the theory of knowledge and the theory of justified belief". In J. Greco (Ed.), Sosa and his critics. Oxford: Wiley-Blackwell.

Maitzen, S. (1995). Our Errant epistemic aim. Philosophy and Phenomenological Research, 55, 869-876.

Merricks, T. (1995). A dilemma for any theory of knowledge. American Philosophical Quarterly, 32, 279-284.

Sartwell, C. (1992). Why knowledge is merely true belief. Journal of Philosophy, 89, 167-180.

Steup, M. (2006). "The analysis of knowledge". Stanford Encyclopedia of Philosophy. http://plato. stanford.edu/entries/knowledge-analysis/.

Sutton, J. (2005). Stick to what you know. Nous, 39, 359-396. 